\title{
A multicenter family practitioners' research on Chronic Obstructive Pulmonary Disease screening using the COPD Assessment Test
}

\author{
Hakan Demirci $^{1}$, Koncuy Eniste ${ }^{2}$, Ebru Onuker Basaran ${ }^{3}$, Gokhan Ocakoglu ${ }^{4}$, Zeynep Yilmaz ${ }^{1}$ and Sumeyye Tuna ${ }^{1}$ \\ ${ }^{1}$ Family Medicine, University of Health Sciences Bursa Yuksek Ihtisas Training and Research Hospital, Bursa, Turkey \\ ${ }^{2}$ Bursa Sakarya Family Practice Unit, Osmangazi, Bursa, Turkey \\ ${ }^{3}$ Bursa FSM Bulvar Family Practice Unit, Nilufer, Bursa, Turkey \\ ${ }^{4}$ Department of Biostatistics, Uludag University, Bursa, Turkey
}

\begin{abstract}
Objectives: Spirometry is known to be a gold standard for the diagnosis of chronic obstructive pulmonary disease (COPD). COPD Assessment Test (CAT) is an eight-item questionnaire currently in use to evaluate patients with COPD. In the present study, we aimed to evaluate if CAT is an adequate tool for screening COPD. Methods: In total, 600 persons aging $\geqslant 40$ years old were randomly selected from three different family practice units located in the city center. CAT was asked to the participants and a spirometry was used to assess pulmonary obstruction. Pulmonary obstruction was defined as forced expiratory volume in first second/forced vital capacity (FEV1/FVC) $<70 \%$ and then COPD diagnosis was confirmed with the reversibility test. The relationship between CAT results and pulmonary function test values was evaluated. Results: In this sampling, the prevalence of COPD was $4.2 \%$. Reliability of the CAT in the study group was acceptable (Cronbach's $\alpha: 0.84)$. The CAT scores was significantly higher in patients with COPD $(P<0.001)$. There was a significant negative correlation between CAT score and FEV1, FVC and FEV1/FVC ratio $(r=-0.31$, $P<0.001 ; r=-0.26, P<0.001 ; r=0.18, P=0.001$ ). Among smokers, phlegm was the predominating symptom $(P=0.01)$. Sensitivity of CAT was $66.67 \%$ and its specificity was $75.15 \%$ to determine COPD. Conclusions: CAT is a reliable questionnaire and there is an apparent relationship between the total CAT scores and COPD. However, CAT's ability to screen COPD is limited since it may miss the symptom-free cases.
\end{abstract}

Key words: COPD Assessment Test; primary care; screening; sensitivity; specificity

Received 28 October 2016; revised 19 April 2017; accepted 17 June 2017;

first published online 17 July 2017

\section{Introduction}

Chronic obstructive pulmonary disease (COPD) is a growing public health problem; it is reported as the leading cause of morbidity and mortality worldwide (Sánchez-Nieto et al., 2016). It is a progressive and debilitating disease and has an important impact on patients' functional performance and quality of life especially in late stages (Ferrer et al., 1997). The

\footnotetext{
Correspondence to: Associate Professor Hakan Demirci, Family Medicine, University of Health Sciences Bursa Yuksek Ihtisas Egitim ve Arastırma Hastanesi, Yildirim, Bursa 16310, Turkey. Email: drhakandemirci@hotmail.com
}

disease is characterized by acute exacerbations that cause its control difficult because of negative effects on quality of life (Seemungal et al., 1998; DomingoSalvany et al., 2002). However, there are usually no complaints during silent periods of the illness. Although screening for COPD is not recommended, attempts to diagnose COPD at an earlier symptomfree stage are continuing [Global Initiative for Chronic Obstructive Lung Disease (GOLD), 2016].

Spirometry is known to be a gold standard for the diagnosis of COPD (Van Schayck et al., 2002; Dales et al., 2005; Enright, 2006). In the absence of spirometric measurements, the diagnosis of COPD is usually postponed. Patients with COPD admit to 
a physician in late stages of the disease generally when the symptoms are apparent. Failure of early diagnosis leads to lack of the treatment, and hence the disease progresses in that time. COPD screening is not yet recommended in asymptomatic cases (Lin et al., 2008; Centers for Disease Control and Prevention, 2012; Ford et al., 2013). The cost of spirometry and need for an educated staff limits its usage. COPD screening with spirometry is not cost-effective and the rate of false positive results limits the test to be used as a screening tool. However, determination of risk groups and screening of COPD in those people by spirometry may be reasonable.

The COPD Assessment Test (CAT) is a short, easy and understandable test to measure quality of life in COPD patients (Dinc et al., 2014). It is an eight-item questionnaire currently in use to evaluate response to treatment in patients with COPD. It is recommended to monitor the adequacy of the treatment of patients with high CAT test results and, if necessary, to change the treatment applied to the individual according to the treatment protocol.

Screening of patients under risk of COPD by CAT was evaluated in previous studies (Raghavan et al., 2012; Yoshimoto et al., 2014). In the present study, we aimed to evaluate if CAT is an adequate tool for screening COPD in general population.

\section{Methods}

The study was designed as a multi-centered crosssectional study. Sampling was made from persons registered to three family physicians located in three different regions in Bursa city. In total, 600 persons, aging 40-65 years old, were randomly selected from patients list of these family practitioners. These persons were invited to the study by phone contact.

Persons who agreed to participate were weighed with light clothes, and their heights' were measured while they were not wearing shoes. A nurse was trained to use spirometer from each family practice office. Forced expiratory volume in first second (FEV1), forced vital capacity (FVC) and peak expiratory flow were measured by a calibrated manual spirometer. The diagnosis of COPD was based on spirometry using GOLD criteria (5). Pulmonary obstruction was defined as FEV1/ FVC $<70 \%$ and patients with pulmonary obstruction were tested for reversibility $20 \mathrm{~min}$ after inhalation of two puff salbutamol.

Primary Health Care Research \& Development 2017; 18: 603-607
Chronic diseases, medications and smoking habits were asked to the patients. Components of CAT test are a cough, phlegm, chest tightness on chest, breathlessness, activity limitation, leaving home despite lung condition, soundly sleeping and having energy. Each items are scored (0-5) as six-point ordinal questionnaire of severity for each item for a possible total score $0-40$ and patients with CAT scores $>10$ revealed test positivity. CAT questionnaire is validated to Turkish by Yorgancioğlu et al. (2011) in 2012.

Exclusion criteria were contraindications to spirometry (active infection, dissecting/unstable aortic aneurysm, current pneumothorax, recent surgery including ophthalmic, thoracic abdominal or neurosurgery), inability to use the spirometry, pregnancy, high fever $\left(>37^{\circ} \mathrm{C}\right)$, lung cancer, previous history of obstructive lung disease and refusal to give informed consent. Patients using corticosteroids, bronchodilators, theophyllines or other medications that may interfere with pulmonary functions were also excluded.

A written informed consent was obtained from the persons who accepted to participate in the study. Ethical approval was approved by the local ethical committee of the hospital and the study was undertaken in accordance with the Declaration of Helsinki.

\section{Statistical analysis}

Variables were reported as mean \pm standard deviation or median (minimum:maximum) values. Normality of distribution of the data was analyzed using Shapiro-Wilk test. According to normality test Mann-Whitney $U$ test was used for between group comparisons. Categorical variables were compared by $\chi^{2}$ test or Fisher's exact test. Relationships between FEV1, FVC and FEV1/FVC measurements, and total CAT scores were analyzed by correlation analysis, Spearman's correlation coefficient was calculated. SPSS (IBM Corporation, 2012) software was used for performing statistical analysis and $P<0.05$ was set at statistical significance.

For the purpose of computing the sensitivity, specificity, positive likelihood ratio, negative likelihood ratio, positive predictive value and negative predictive value, the spirometry was designated the gold standard. This gold standard results were compared with the presence or absence of CAT positivity (CAT scores $>10$ ). 


\section{Results}

In total, 357 persons out of 600 participated in the study. Three persons failed to exhale to spirometry properly and nine patients who knew that they had COPD and one person with a diagnosis of lung cancer were excluded from the study. There were 15 cases of COPD $(4.2 \%)$ out of 357 participants. The mean age of the female participants $(n=200)$ was $55.71 \pm 8.46$ years, and the mean age of male participants $(n=157)$ was $55.26 \pm 9.05$ years.

For the internal consistency of the CAT questionnaire Cronbach's $\alpha$ reliability coefficient was 0.84 . There were 95 participants who have total CAT scores $>10$ and there were 10 patients with COPD in this group. Sensitivity, specificity, likelihood ratios and predictive values are shown in Table 1 . The positive likelihood ratio was 2.68 while the negative predictive value of the CAT was $98 \%$ to diagnose COPD in the study group.

Total CAT scores and scores of all the questions were significantly higher in patients with COPD (Table 2). Soundly sleeping was the most significant item associated with the CAT. There were 85 current smokers $(23.8 \%)$ and CAT scores were not correlated with smoking status. Only the scores to the phlegm were significantly higher among current smokers (Table 3 ).

Patients with co-morbid diseases $(n=248)$ had CAT scores [6 (0:38)] higher than CAT scores [3 $(0: 25)]$ of patients with no co-morbid diseases $(n=109) \quad(P<0.001)$. Patients who were using medication for any specific illness $(n=236)$ had CAT scores [7 (0:38)] higher than CAT scores [3 (0:31)] of patients who used no medication $(n=121) \quad(P<0.001)$. Patients with a history of depression who were using antidepressant drugs had higher scores of having energy $(P=0.014)$

Table 1 Statistics for CAT to estimate COPD diagnosed with spirometry

\begin{tabular}{lcc}
\hline Statistic & Value & 95\% Confidence interval \\
\hline Sensitivity & $66.67 \%$ & $38.38-88.18 \%$ \\
Specificity & $75.15 \%$ & $70.21-79.64 \%$ \\
Positive likelihood ratio & 2.68 & $1.79-4.01$ \\
Negative likelihood ratio & 0.44 & $0.22-0.91$ \\
Positive predictive value & $10.53 \%$ & $7.29-14.96 \%$ \\
Negative predictive value & $98.09 \%$ & $96.16-99.06 \%$
\end{tabular}

CAT $=$ Chronic Obstructive Pulmonary Disease (COPD) Assessment Test.
Table 2 Relationship between the CAT results and COPD diagnosed with spirometry

\begin{tabular}{lllr}
\hline & $\begin{array}{llr}\text { COPD (-) } \\
(n=342)\end{array}$ & $\begin{array}{l}\text { COPD (+) } \\
(n=15)\end{array}$ & $P$-value \\
\hline CAT (total) & $5(0: 34)$ & $15(2: 38)$ & $<0.001$ \\
Cough & $0(0: 5)$ & $1(0: 5)$ & 0.002 \\
Phlegm & $0(0: 5)$ & $1(0: 5)$ & 0.007 \\
Tightness on chest & $0(0: 5)$ & $2(0: 5)$ & 0.001 \\
Breathlessness & $1(0: 5)$ & $3(0: 5)$ & 0.012 \\
Activity limitation & $0(0: 5)$ & $1(0: 5)$ & 0.002 \\
Leaving home despite & $0(0: 5)$ & $1(0: 5)$ & 0.001 \\
$\quad$ lung condition & & & \\
Sleeping soundly & $0(0: 5)$ & $2(0: 5)$ & $<0.001$ \\
Having energy & $1(0: 6)$ & $3(0: 5)$ & 0.005 \\
\hline
\end{tabular}

CAT $=$ Chronic Obstructive Pulmonary Disease (COPD) Assessment Test.

Table 3 The relationship between CAT scores and smoking habits

\begin{tabular}{|c|c|c|c|}
\hline & $\begin{array}{l}\text { Current } \\
\text { smokers } \\
(n=85)\end{array}$ & $\begin{array}{l}\text { Current non- } \\
\text { smokers } \\
(n=272)\end{array}$ & $P$-value \\
\hline CAT (total) & $6(0: 31)$ & $5(0: 38)$ & 0.502 \\
\hline Cough & $1(0: 5)$ & $0(0: 5)$ & 0.065 \\
\hline Phlegm & $1(0: 5)$ & $0(0: 5)$ & 0.010 \\
\hline $\begin{array}{l}\text { Tightness on } \\
\text { chest }\end{array}$ & $1(0: 5)$ & $0(0: 5)$ & 0.328 \\
\hline Breathlessness & $1(0: 5)$ & $1(0: 5)$ & 0.670 \\
\hline Activity limitation & $0(0: 5)$ & $0(0: 5)$ & 0.393 \\
\hline $\begin{array}{l}\text { Leaving home } \\
\text { despite lung } \\
\text { condition }\end{array}$ & $0(0: 4)$ & $0(0: 5)$ & 0.083 \\
\hline Sleeping soundly & $0(0: 5)$ & $0(0: 5)$ & 0.262 \\
\hline Having energy & $1(0: 5)$ & $1(0: 6)$ & 0.111 \\
\hline
\end{tabular}

(Table 4). Antidepressant usage frequency among patients without COPD $(n=351)$ was $12 \%(n=42)$ while its frequency was $33.3 \% \quad(n=5)$ among patients with COPD $(n=15)$ but there was no statistically significant difference between these two groups $(P=0.161)$.

When the relationships between FEV1, FVC and FEV1/FVC ratio and total CAT score were examined, it was seen that there was a significant negative correlation between CAT score and related measures $(r=-0.31, P<0.001 ; r=-0.26$, $P<0.001 ; r=0.18, P=0.001)$. The change in total CAT scores is affected inversely from the change in FeV1, FVC and FeV1/FVC ratios.

Primary Health Care Research \& Development 2017; 18: 603-607 
Table 4 The relationship between CAT scores and antidepressant usage

\begin{tabular}{llcc}
\hline & $\begin{array}{l}\text { No antidepressant use } \\
(n=313)\end{array}$ & $\begin{array}{l}\text { Antidepressant use } \\
(n=44)\end{array}$ & $P$-value \\
\hline CAT (total) & $5(0: 38)$ & $6(0: 21)$ & 0.197 \\
Cough & $0(0: 5)$ & $0(0: 3)$ & 0.522 \\
Phlegm & $0(0: 5)$ & $0.5(0: 3)$ & 0.774 \\
Tightness on chest & $0(0: 5)$ & $1(0: 4)$ & 0.481 \\
Breathlessness & $1(0: 5)$ & $1(0: 5)$ & 0.773 \\
Activity limitation & $0(0: 5)$ & $0(0: 5)$ & 0.195 \\
Leaving home despite lung & $0(0: 5)$ & $0(0: 3)$ & 0.143 \\
condition & $0(0: 5)$ & $0(0: 5)$ & 0.196 \\
Sleeping soundly & $1(0: 6)$ & $2(0: 5)$ & 0.014 \\
Having energy & & & \\
\hline
\end{tabular}

CAT $=$ Chronic Obstructive Pulmonary Disease Assessment Test.

\section{Discussion}

As a result of our study, in this sampling COPD frequency was $4.2 \%$. Total CAT scores were higher in patients with COPD and the item 'soundly sleeping'was the most significant variable. Sensitivity and specificity of CAT to diagnose COPD were 66.67 and $75.15 \%$, respectively.

In the present study, the COPD prevalence was lower than the results of previous studies (Gunen et al., 2008; Deveci et al., 2011; Arslan et al., 2013; Dikis et al., 2015). There might be some reasons to explain the low frequency of COPD in the present study. Fight against smoking in Turkey with the campaign named as $100 \%$ smokeless air may be the first reason. Recently, wide spreading of heating with natural gas instead of coal may be the other. Car exhaust examinations have been carried more seriously than before in the last decade in Turkey, and it might have affected the dust in the air.

In a previous study composed of smokers, it was shown that CAT results were most associated with phlegm and breathlessness (Raghavan et al., 2012). In the present study, phlegm was significantly associated with smoking habits. We also found that CAT scores were higher in patients with COPD and the item of 'soundly sleeping' was the most significantly associated item. CAT positive cases had a higher probability of having COPD and the sensitivity, specificity and predictive values we recorded were similar to the results in the literature.

COPD is usually the disease of elderly and so some co-morbid diseases like diabetes mellitus, depression and hypertension may accompany COPD. These co-morbid diseases are shown to interfere with spirometric results (Omachi et al., 2009; Joo et al., 2013; Battaglia et al., 2015). In the present study, co-morbidities were detected as a confounding factor for CAT evaluation. The higher the number of co-morbidities the higher was the total CAT score. Moreover, it has been shown that CAT scores elevated with the presence of depression (Silva Júnior et al., 2014). We also noticed that patients with depression who currently using antidepressant, had higher scores with the item 'having energy.' Further research is needed to evaluate these relationships in depth.

One of the limitations of the study was the manual spirometry used to detect pulmonary functions. But, manual spirometry is the instrument that is currently available at primary care centers. The other limitation was the small number of participants involved in the study which prevented us to make generalizations with the results we obtained.

In conclusion, CAT is a reliable questionnaire and there is an apparent relationship between its scores and pulmonary function test results. However, CAT's ability to screen COPD is limited since it misses symptom-free cases at the early stages of the disease.

\section{Acknowledgments}

The authors thank to Nazli Demirci (Philologist) for her contribution to the study.

\section{Financial Support}

None. 


\section{Conflicts of Interest}

None.

\section{References}

Arslan, Z., Ilgazlı, A., Etiler, N. and Hamzaoğlu, O. 2013: Prevalence of chronic obstructive pulmonary disease in Kocaeli: an industrialised city in Turkey. Balkan Medical Journal 30, 387-93.

Battaglia, S., Basile, M., Scichilone, N. and Bellia, V. 2015: Prevalence of co-morbidities and severity of COPD. COPD 12, 390-94.

Centers for Disease Control and Prevention. 2012: Chronic obstructive pulmonary disease among adults - United States, 2011. Morbidity and Mortality Weekly Report 61, 938-43.

Dales, R.E., Vandemheen, K.L., Clinch, J. and Aaron, S.D. 2005: Spirometry in the primary care setting. Influence on clinical diagnosis and management of airflow obstruction. Chest 128, 2443-447.

Deveci, F., Deveci, S.E., Turkoglu, S., Turgut, T., Kirkil, G., Rahman, S., Açik, Y. and Muz, M.H. 2011: The prevalence of chronic obstructive pulmonary disease in Elazig, Eastern Turkey. European Journal of Internal Medicine 22, 172-76.

Dikis, O.S., Dulger, S.U., Karadag, M. and Demirci, H. 2015: COPD cases detected by Spirometry on world COPD day event in Bursa. European Respiratory Journal $1,61-65$.

Dinc, M., Maden, E. and Uzun, K. 2014: The availability of COPD Assessment Test (CAT) in determination of risk of early hospitalization in chronic obstructive pulmonary disease patients and its correlation with pulmonary function tests, dyspnea measurement scales and St George respiratory questionnaire. European Respiratory Journal 44, 4726.

Domingo-Salvany, A., Lamarca, R., Ferrer, M., Khalaf, A., Marrades, R.M., Monsó, E., Serra-Batlles, J. and Antó, J.M. 2002: Health-related quality of life and mortality in male patients with chronic obstructive pulmonary disease. American Journal of Respiratory and Critical Care Medicine 166, 680-85.

Enright, P. 2006: Does screening for COPD by primary care physicians have the potential to cause more harm than good? Chest 129, 833-34.

Ferrer, M., Alonso, J., Morera, J., Marrades, R.M., Khalaf, A., Aguar, C., Plaza, V., Prieto, L. and Anto, J.M. 1997: Chronic obstructive pulmonary disease stage and health-related quality of life. Annals of Internal Medicine 127, 1072-79.

Ford, E.S., Croft, J.B., Mannino, D.M., Wheaton, A.G., Zhang, X. and Giles, W.H. 2013: COPD surveillance - United States, 1999-2011. Chest 144, 284-305.

Global Initiative for Chronic Obstructive Lung Disease (GOLD). 2016: Global strategy for the diagnosis, management and prevention of COPD. Retrieved 25 February 2017 from http:// goldcopd.org/.
Gunen, H., Hacievliyagil, S.S., Yetkin, O., Gulbas, G., Mutlu, L.C. and Pehlivan, E. 2008: Prevalence of COPD: first epidemiological study of a large region in Turkey. European Journal of Internal Medicine 19, 499-504.

IBM Corporation. 2012. IBM SPSS statistics for Windows, version 21.0. Armonk, NY: IBM Corporation.

Joo, M.J., Sharp, L.K., Au, D.H., Lee, T.A. and Fitzgibbon, M.L. 2013: Use of spirometry in the diagnosis of COPD: a qualitative study in primary care. COPD 10, 444-49.

Lin, K., Watkins, B., Johnson, T., Rodriguez, J.A. and Barton, M.B. 2008: Screening for chronic obstructive pulmonary disease using spirometry: summary of the evidence for the US Preventive Services Task Force. Annals of Internal Medicine 148, 535-43.

Omachi, T.A., Katz, P.P., Yelin, E.H., Gregorich, S.E., Iribarren, C., Blanc, P.D. and Eisner, M.D. 2009: Depression and health-related quality of life in chronic obstructive pulmonary disease. The American Journal of Medicine 122, 778-79.

Raghavan, N., Lam, Y.M., Webb, K.A., Guenette, J.A., Amornputtisathaporn, N., Raghavan, R., Tan, W.C., Bourbeau, J. and O'Donnell, D.E. 2012: Components of the COPD Assessment Test (CAT) associated with a diagnosis of COPD in a random population sample. $C O P D$ 9, 175-83.

Sánchez-Nieto, J.M., Andújar-Espinosa, R., Bernabeu-Mora, R., Hu, C., Gálvez-Martínez, B., Carrillo-Alcaraz, A., ÁlvarezMiranda, C.F., Meca-Birlanga, O. and Abad-Corpa, E. 2016: Efficacy of a self-management plan in exacerbations for patients with advanced COPD. International Journal of Chronic Obstructive Pulmonary Disease 11, 1939-947.

Seemungal, T.A., Donaldson, G.C., Paul, E.A., Bestall, J.C., Jeffries, D.J. and Wedzicha, J.A. 1998: Effects of exacerbation on quality of life in patients with chronic obstructive pulmonary disease. American Journal of Respiratory and Critical Care Medicine 157, 1418-422.

Silva Júnior, J.L., Conde, M.B., de Sousa Corrêa, K., da Silva, C., da Silva Prestes, L. and Rabahi, M.F. 2014: COPD Assessment Test (CAT) score as a predictor of major depression among subjects with chronic obstructive pulmonary disease and mild hypoxemia: a case-control study. $B M C$ Pulmonary Medicine 14, 186.

Van Schayck, C., Loozen, J.M.C., Wagena, E., Akkermans, R.P. and Wesseling, G.J. 2002: Detecting patients at a high risk of developing chronic obstructive pulmonary disease in general practice: cross-sectional case finding study. BMJ 324, 1370.

Yorgancioğlu, A., Polatl, M., Aydemir, Ö., Yılmaz, D.N., Kırkıl, G., Naycı, A.S., Köktürk, N., Uysal, A., Akdemir, S.E., Ozgur, E.S. and Günakan, G. 2011: Reliability and validity of Turkish version of COPD assessment test. Tuberkuloz ve toraks 60, 314-20.

Yoshimoto, D., Nakano, Y., Onishi, K., Hagan, G. and Jones, P. 2014: The relationship between the COPD Assessment Test score and airflow limitation in Japan in patients aged over 40 years with a smoking history. International Journal of Chronic Obstructive Pulmonary Disease 9, 1357-363. 